\title{
POLITICAL ENGAGEMENT AND CRIME VICTIMIZATION: A CAUSAL ANALYSIS
}

\author{
Involucramiento político y victimización delictiva: un análisis causal \\ Engajamento político e vitimização do crime: uma análise causal
}

\author{
ISABEL LATERZO (1i) ilaterzo@live.unc.edu 1 \\ 1 University of North Carolina at Chapel Hill \\ Submission: 2020-08-23 \\ Accepted: 2021-02-01 \\ First View: 2021-04-05 \\ Publication: 2021-05-31
}

\begin{abstract}
Keywords: crime victimization; political engagement; Brazil; panel data; identities

Abstract

In recent years, research has demonstrated that crime victimization serves as a catalyst to political engagement. However, much of this work has not addressed two key issues: 1) the true causality of this relationship, and 2) how victims' identities and personal experiences might influence this relationship. This paper tackles these issues by testing the effect of victimization on non-electoral engagement using the Two-City, Six-Wave panel survey administered in Brazil between 2002 and 2006. It finds that the causal relationship between victimization and engagement only exists for participation in political party meetings. Furthermore, when exploring the role of individual identity and community context, only men, those who live in safe neighborhoods, and White Brazilians experience an increase in their engagement. Meanwhile, women, those in unsafe neighborhoods, and Afro-Brazilians do not experience such an increase. Those who have not experienced discrimination also increase their participation, while those who have experienced discrimination do not.
\end{abstract}




\section{Palabras clave:} victimización delictiva; involucramiento político; Brasil; datos de panel; identidades

Palavras-chave: vitimização do crime; engajamento político; Brasil; dados do painel; identidades

\section{Resumen}

En los últimos años, las investigaciones han demostrado que la victimización por la delincuencia sirve de catalizador para el involucramiento político. Sin embargo, gran parte de estos trabajos no han abordado dos cuestiones importantes: 1) la verdadera causalidad de esta relación, y 2) cómo las identidades y experiencias personales de las víctimas pueden influir en esta relación. Este trabajo aborda estas cuestiones poniendo a prueba el efecto de la victimización en el involucramiento no electoral utilizando la encuesta de panel de Dos Ciudades, Seis Ondas en Brasil entre 2002 y 2006 . Se encuentra que la relación causal entre la victimización y el involucramiento sólo existe para la participación en las reuniones de los partidos políticos. Además, cuando se explora el papel de la identidad individual y el contexto comunitario, sólo los hombres, los que viven en barrios seguros y los brasileños blancos experimentan un aumento de su involucramiento. En cambio, las mujeres, los que viven en barrios inseguros y los afrobrasileños no experimentan dicho aumento. Los que no han sufrido discriminación también aumentan su participación, mientras que los que han sufrido discriminación no lo hacen.

Nos últimos anos, pesquisas demonstraram que a vitimização do crime serve como um catalisador para o engajamento político. No entanto, grande parte deste trabalho não tratou de duas questões importantes: 1) a verdadeira causalidade desta relação, e 2) como as identidades das vítimas e as experiências pessoais podem influenciar esta relação. Este trabalho aborda estas questões testando o efeito da vitimização no engajamento não-eleitoral usando a pesquisa do painel Duas Cidades, Seis Ondas administrada no Brasil entre 2002 e 2006 . Ele conclui que a relação causal entre vitimização e engajamento só existe para participação em reuniões de partidos políticos. Além disso, ao explorar o papel da identidade individual e do contexto comunitário, apenas os homens, aqueles que vivem em bairros seguros e os brancos-brasileiros experimentam um aumento em seu engajamento. Enquanto isso, as mulheres, aqueles que vivem em bairros inseguros e os afro-brasileiros não experimentam tal aumento. Aqueles que não sofreram discriminação também aumentam sua participação, enquanto aqueles que sofreram discriminação não o fazem.

\section{INTRODUCTION}

It is well understood that Latin America is home to some of the world's most violence-stricken nations. Countries such as El Salvador, Honduras, Brazil, Colom$\mathrm{bia}$, and Mexico have some of the highest rates of intentional homicides, ranging between 25 to 62 per 100,000 people. Meanwhile, the global average is only 6.1 per 100,000 (Data UNODC, 2017). In addition to homicide, the prevalence of other types of violent crime mean that Latin America is home to thousands of crime survivors. Although our understanding of the quantity of such individuals is flawed, with underreporting for violent crimes sometimes reaching up to $90 \%$ (Laterzo, 2020), we know such victims represent a large portion of society. 
Not only do crime victims represent a significant proportion of both the population and the electorate, but violence also has meaningful political consequences. These include, but are not limited to, effects on democratic values, political participation and engagement, and voting behavior (Ley, 2013). One of such areas that remains under-explored is that of political participation and engagement, such as participation in protests, engagement in political conversations, and voting. For the purposes of this paper, I will refer to various non-electoral forms of political participation and engagement as simply "political engagement"1. Many argue that there is a direct causal relationship between victimization and these practices. These literatures are typically divided among those that explore the effect of victimization on non-electoral (Bateson, 2012; Brooks, 2014) and electoral (Ley, 2017; Ley, 2018; Trelles \& Carreras, 2012) forms of engagement. Some explore both forms (Blattman, 2009). In both camps, there is disagreement about whether or not victimization and violence lead to increased, or decreased, engagement.

In this article, I argue that we can see two main gaps in prior research assessing the role victimization plays in altering political engagement patterns. First, there is a methodological issue. Previous studies often utilize single-year cross-sectional data to suggest a relationship between victimization and engagement. Unfortunately, such an approach is misleading, as without temporal variation and tracking of the same individuals, it is difficult to assert a true, individual-level causal relationship. Only certain authors, such as Oosterhoff, Kaplow, Layne \& Pynoos (2018), have been able to actually trace individual level data to isolate the effects of victimization on engagement ${ }^{2}$. Thus, there is limited evidence of the causal nature of this relationship. Therefore, it is quite possible that the relationship between victimization and engagement is simply associational.

Second, the disagreement in the literature could be due to the fact that that the effect of victimization and violence on political engagement is dependent on one's community context and social identity. The literature often assesses societies as relatively uniform in citizen exposure to violence and victimization. Or, authors have treated countries with higher or lower levels of violence as relatively

1. As will be discussed, scholars who examine these various types of political engagement use a variety of terms to describe them. For example, Bateson (2012) classifies reported attendance at community meetings, political meetings, and town meetings; level of interest in politics; and attempts to convince others of political views all as forms of "participation" while Hadzic, et al. (2020), Hadzic \& Tavits (2019), and others use the term "engagement" to refer to concepts such as the intention to vote and one's interest in politics. Furthermore, there is significant debate as to what exactly comprises the realm of political "participation," for example see (Van Deth, 2014). For this reason, I choose to utilize the more encompassing term of "political engagement" to refer to a variety of possible means of engaging in politics, across the spectra of formality and conventionality.

2. In addition, Blattman (2009) does, notably, substantiate his findings with qualitative interviews, giving more legitimacy to his causal claims. 
comparable. However, this is not the case. Rather, individuals and communities that have higher rates of victimization are unique in their engagement patterns, and should be researched as such. For example, Ley (2018) demonstrates that in particularly insecure areas, the criminal context of a community can "transcend" one's personal victimization experience. Furthermore, there is substantial evidence of individual-level variation in engagement patterns based on one's identity and experience - such as one's gender, ethnicity, or experience with discrimination (Desposato \& Norrander, 2009; Oskooii, 2016; Hadzic \& Tavits 2019). Previous literature has done little to explore the intersection of identity and victimization, and how such intersections may influence engagement patterns.

I thus argue there are two main gaps in the literature that research should further explore: the causal link between victimization and political engagement, and the effects of context, identity, and individual experience on this relationship. This paper seeks to fill these gaps by first testing the relationship between victimization and political engagement using panel data, helping to isolate a causal relationship, and second, by further determining what factors about victims affect this relationship, if it exists.

I take advantage of the "Two-City, Six-Wave Panel Survey, Brazil" administered in Caxias do Sul, Rio Grande do Sul and Juiz de Fora, Minas Gerais by Baker, Ames, Sokhey \& Renno (2015). The survey was administered twice per year in 2002 , 2004 , and 2006 as a panel. It includes questions on quality of life, various political engagement measures, identification, and victimization. Using this survey allows me to test direct causality between witnessing or experiencing crime victimization and subsequent political engagement. About $18 \%$ of participants experienced or witnessed crime victimization in Wave 4 of the survey ${ }^{34}$. I am able to examine their levels of engagement prior to and following this occurrence.

Following my examination of causality, I also consider how victims' social groups and history with discrimination matter. I look at those who have historically experienced marginalization, such as certain ethnic or racial groups, women, and the socially marginalized, and how their engagement patterns differ from those who have not experienced such historical marginalization. Further, I also examine differing patterns among those who report experiencing discrimination based on their race, gender, neighborhood of residence, or clothing (a proxy for perceived

3. This is of the individuals who responded to the question soliciting information about victimization in Wave 4.

4. Unfortunately, this question does include both victimization and witnessing of crime. However, there is precedent in using such questions to explore the effects of crime victimization overall. For example, Bateson (2012) and Visconti (2019) both rely on similar (or the same) questions in testing the effect of victimization on various variables. 
socoeconomic status) ${ }^{5}$ versus those who have not. I choose to examine these groups as research indicates there are notably different engagement patterns among those belonging to different identities and social groups (Desposato \& Norrander, 2009) and those who have experienced discrimination (Barreto \& Woods, 2005; Oskooii, 2016). If we are to see shocks to political engagement after victimization, examining particular groups and populations with such differences should be a fruitful place to explore.

To properly examine these effects, I use a difference in difference (DiD) design, a quasiexperimental design used to study causal relationships. For each group, and its countergroup, I conduct a DiD experiment using victimization as the treatment. I examine the effect of this treatment on three different measures of political engagement. I then compare the average treatment effect (ATE) of victimization experienced by each to its counterpart. For example, I compare the ATE of victimization on party engagement levels for Afro-Brazilians to the same ATE but for White Brazilians.

Overall, this study results in two main findings: First, there is mixed evidence supporting a causal relationship between victimization and engagement. Across the entire pooled sample, among the three forms of non-electoral engagement examined I only observe an increase in party engagement following victimization. This research design thus indicates that victimization is a less robust cause of engagement than previously assumed and the shock of victimization on political engagement is likely mode specific.

However, breaking down the surveyed population to compare various individual groupings, including comparing those who live in safe versus unsafe neighborhoods, women versus men, and those who report experiencing discrimination, reveals more interesting results. Across subgroups, I see certain groups (i.e., men, those who live in safe neighborhoods, the non-poor, White Brazilians, and those who have not experience discrimination) experience a positive shock to their engagement following victimization. But, their counterpart groups do not experience this shock. However, such results should be interpreted conservatively as confidence intervals of the ATEs for each group overlap in every case, making this conclusion only a potential suggestion.

The following sections will proceed as follows. First, I will explore the extant literature on political engagement as it relates to engagement based on the subgroupings I identify (i.e, gender, race, wealth, neighborhood safety, and experience with discrimination). I then explore the relevance of this in the context of Brazil. Subsequently, I review my research design and demonstrate my results. I then conclude and discuss potential avenues for further research.

5. This measure has been used as a proxy for socioeconomic status in past studies, for example see Bueno \& Dunning (2017). 


\section{VICTIMIZATION'S THEORIZED EFFECT ON POLITICAL ENGAGEMENT}

This paper explores the role that victimization plays in affecting one's political engagement. Political engagement has been argued to be quite responsive to various individual shocks, one of which is violence. Research across country contexts haves argued for a direct link between exposure to violence and an increase in various forms of political engagement. In the context of Uganda, exposure to violent conflict is shown to increase one's propensity to vote and participate in community organizations, among other measures (Blattman, 2009). But even outside of wartime scenarios, various scholars argue that personal victimization, such as experiencing robbery or a break-in, is associated with heightened political engagement in a variety of venues. Bateson (2012) demonstrates this pattern across regions using common "barometer" surveys. She shows that victims of crime (or in some cases those with family members who were victims) participate more in community action, community meetings, protest, town meetings, political meetings, political conversations, and group leadership in addition to having higher levels of political interest and engagement in political persuasion. The fact that these results are found across disparate country contexts is indeed compelling. Furthermore, as previously discussed this relationship has been examined with regard to both electoral and non-electoral forms of engagement. Although many of these authors argue for a clear positive relationship between victimization and engagement, there is actually much disagreement as to the role that violence and victimization plays in influencing both electoral and non-electoral engagement and participation. Some argue that violence is in fact demotivating, and in more violent contexts we see less electoral and non-electoral engagement (Ley, 2018; Brooks, 2014).

Indeed, regardless of the directionality of this relationship, a crucial component of these arguments is that victimization (and/or violence) is temporally prior to engagement levels. That is, exposure to victimization affects engagement (whether positively or negatively), making this a causal relationship. These conclusions have been made at both the individual (Bateson, 2012; Blattman, 2009; Oosterhoff et al., 2018; Brooks, 2014) and community level (Trelles \& Carreras, 2012; Ley, 2017; Ley, 2018). However, in terms of individual-level arguments, the majority of the literature arguing for this causal relationship uses singleyear, cross-sectional data. These pieces find correlations between victimization or related themes (e.g., perceptions of insecurity) and engagement, with theories that are largely causal. However, unfortunately, this cross-sectional data does not allow for causal conclusions as the temporal relationship between the exposure to victimization and the engagement levels measured cannot be determined. Thus, the method used to test these causal theories does not truly allow for causal conclusions, and rather reveals associations between victimization and engagement. These results are still quite impressive and useful in the study of political engagement, but there remains some 
adjudication to be done. Does violence and victimization truly lead to changes in engagement? Or is it just an association explained by other factors? It is possible by adding in a temporal element to these examinations, research can determine how exactly victimization affects engagement, if at all.

\section{The Role of Context and Individual Identities}

In addition to questions about causality and methodology, much extant literature leaves out a degree of specificity that is necessary to understand political engagement patterns. By no means are all victims the same and neither are their in-groups, such as the communities in which they live or the identities to which they belong. Multiple streams of research demonstrate that other key factors, apart from victimization, affect engagement patterns. These include community context, individual identities, and past experiences. It is possible that such factors influence, or mediate, the supposed relationship between victimization and engagement.

One key variable to consider is community context, or the environment in which citizens live and participate in politics. Country and community-specific engagement literature demonstrates to us that political engagement patterns in the context of violence and victimization are not all created equal. For example, in both Mexico and Brazil, research indicates citizens' engagement is mediated by the overall level of violence of their communities (Trelles \& Carreras, 2012; Bravo \& Hernández, 2012; Brooks, 2014; Ley, 2018). Specifically, Trelles \& Carreras (2012) note that in contexts of high criminal violence, citizens actually abandon public channels of engagement. When comparing Mexican municipalities, those with higher levels of violence have the lowest levels of voter turnout. This is due to disenchantment with the political sphere, or fear of the risks to their safety in public places. Further, Brooks (2014) demonstrates that citizens in Brazil who lack effective means to protect themselves from victimization become less active citizens. Thus, such research shows us that victimization and violent contexts do not always lead to increased engagement.

In addition, we know that individuals of different identities and backgrounds have varying patterns of engagement. Although this has not been often applied to the context of crime victimization, there is reason to believe that different kinds of victims might respond in distinct manners to victimization. There is evidence, for example, that individuals of different gender identities, ethnic and racial backgrounds, and socioeconomic status have various patterns of engagement, particularly in contexts of insecurity and violence. Furthermore, individuals who have experienced a history of discrimination on the basis of these traits and identities also behave differently in the realm of engagement. 
With regard to gender, research demonstrates that violence has clear, gendered effects on political engagement. For example, Hadzic \& Tavits (2019) show that violence increases engagement among men while reducing it among women, specifically in the context of a post-conflict society. Bardall, Bjarnegård \& Piscopo (2020) argue that violence can have varied gendered impacts for a variety of reasons. Even if conflict or violence is not explicitly motivated by gender, women may find violence to be particularly threatening. If we consider the gendered nature of one's political opportunity structure, women may be more risk-averse compared to men in politics, as they feel more vulnerable and responsible for caring for their families. Furthermore, we see in Latin America specifically that a gender-gap exists across forms of electoral and non-electoral politics, even without considering the influence of victimization. Across country contexts, women tend to participate less than men, although the size of this gap depends on a variety of factors (e.g., age, employment) (Desposato \& Norrander, 2009).

In addition, significant scholarly work demonstrates differing patterns of political engagement among distinct racial and ethnic identities. The variance in such patterns can be described by multiple factors, including socioeconomic status, psychological resources, social and societal connectedness, group identity and consciousness, and group (or inter-group) conflict (Leighley \& Vedlitz, 1999). Such patterns exist in Latin America as well, where research has shown White individuals tend to participate more in political associations compared to their Black counterparts. However, socioeconomic status can have a mediating effect - a White individual's propensity to participate politically is more affected by income than a similar Black individual's propensity (Bueno \& Fialho, 2009). The intersection of race, ethnicity and victimization, however, has only been minimally explored. But, there is reason to believe victimization might affect individuals of different racial and ethnic identities in distinct manners. For example, we know that violence, particularly that which has racial undertones, has been shown to affect other political behavior outcomes (e.g., vote choice) in distinct ways across such groups (Hadzic et al., 2020).

Finally, we also know one important individual-level factor that can influence one's political engagement is socioeconomic status (SES). Brady, Verba \& Schlozman (1995) have argued, for example, that those of lower SES often participate less, as they have fewer resources key to engagement - time, money, and civic skills. More recent research has echoed such results, showing that those of lower SES tend to participate at lower levels, but with some nuance. The inequality of a society interacts with important SES components, such as income. Particularly in the realm of unconventional political engagement, income negatively interacts with inequality explaining why we see those of lower SES participating more in unconventional forms of politics (e.g., protest) as compared to conventional politics (e.g., voting) (Cicatiello, Ercolano \& Gaeta, 2015). Violence and economic insecurity also have an important and dynamic relationship. Brooks (2014) argues that it 
is not necessarily the poorest individuals who do not participate, but a wider category of the insecure. She argues that even those who live just above the poverty line, but do not have sufficient resources to adequately "hedge alone the risks of everyday life", including criminal threats, are less likely to participate politically.

In addition to differing patterns of engagement based on these outlined identities and factors, individuals corresponding to these groups often face discrimination. Political discrimination based on gender, race, ethnicity, socioeconomic status, or neighborhood of residence can lead to changes in engagement as well. Many scholars contend that political discrimination, particularly by political institutions, can motivate political engagement (Barreto \& Woods, 2005; Oskooii, 2016). Importantly, however, societal discrimination can have differing effects - perceptions of society based discrimination can lead to increases in in-group political engagement (e.g., community organizations) but decreased participation in mainstream arenas (e.g., electoral participation) (Oskooii, 2016; Oskooii, 2020). Other studies also show that perceptions of discrimination against oneself can lead to decreased voter registration and voting (Schildkraut, 2005). Thus, the effect of discrimination on engagement is more difficult to parse apart. It has yet to be explored particularly in the context of victimization.

\section{Theoretical Expectations}

In this analysis, I seek to re-test previous arguments about the effect of victimization on political engagement. In particular, I re-examine this relationship in light of two main contentions I present. First, a research design that allows for a better causal argument to be tested at the individual level is needed. Thus, I leverage a panel survey in the context of Brazil to be able to ensure the "treatment" of victimization is temporally prior to any subsequent engagement observed. Second, I break down the population into various subgroups to understand how such groups might experience a change in their engagement following victimization differently. Because of the various factors discussed above, such as access to resources and possible risk-aversion among various groups, if a relationship exists between victimization and engagement, it should be most visible when parsing apart respondents by such factors.

When examining one's neighborhood context, previous research suggests a clear relationship. The insecurity of one's community should lead individuals to abstain from political engagement, possibly out of fear of further exposure to violence. Thus, we should expect that victimization for those living in insecure neighborhoods should not serve as a substantial shock to engagement. In other words, the effect of the treatment (victimization) in unsafe neighborhoods should produce little effect. Rather, it is more plausible that this shock is present among residents who live in safe neighborhoods. 
In terms of sociodemographic characteristics, we should expect certain clear relationships. Based on previously discussed literature, it seems women not only participate in politics less overall compared to men, but detract from the political arena when exposed to violence. If women are truly more risk-averse than men and participate less in contexts of violence, we should not see a shock to their engagement following victimization, while we should expect to see one among men.

In terms of race and ethnicity, there is clear evidence that racial and ethnic groups which have been historically marginalized (e.g., those of indigenous or African descent in the case of Brazil) tend to participate less in politics. Although there has been little analysis connecting engagement patterns and victimization among different ethnic and racial identities, I expect certain patterns to hold following victimization. That is, victimization should not serve as a meaningful shock to political engagement among individuals of historically marginalized ethnicities and races. Given that such groups typically have fewer resources at their disposal to engage in politics (Leighley \& Vedlitz, 1999), feel political systems are unfair and unresponsive to their needs (Flesken \& Hartl, 2020), and have lower sense of belonging in a system (Williams, 2000) we should not see an increase in engagement following victimization. Rather, such a shock might be present across groups that have not historically experienced marginalization, such as White individuals. In the context of this research, I particularly explore the difference in engagement levels of White and Afro-Brazilians. The former group has experienced clear privilege, access to resources, and political representation in Brazil while the latter continues to experience a lack of representation and marginalization by the state and society (Telles, 2007; Janusz \& Campos, 2018).

Further, those of lower SES are also unlikely to increase their engagement following victimization. As articulated by Brooks (2014), it is particularly those at the intersection of economic and physical insecurity who participate the least in politics. However, this could be engagement-mode specific, as evidence does show higher levels of engagement in more informal modes of political engagement among the poor.

When examining the role of discrimination, it is less clear what relationship we should expect. Past research shows that discrimination can both lead to increased and decreased engagement levels. Further, there has been little research that examines if violence or insecurity affects those who have experienced victimization in a distinct manner. Thus, this study hopes to adjudicate how violence might influence engagement among individuals who have experienced discrimination, whether it be on the basis of their race, gender, socioeconomic status, or neighborhood of residence. It is possible that such individuals experience an increase or decrease in engagement compared to those who have not experienced discrimination. It is also possible there is no effect at all. 


\section{Brazil and Panel Survey Contexts}

As previously discussed, Brazil represents a country plagued by high, and increasing, levels of violence. Between 2000 and 2017, the homicide rate in Brazil grew from 23.7 to 30.5 intentional homicides per 100,000 people. The global average in 2017 was only 6.1 per 100,000 people (Data UNODC, 2017). Homicide levels do not even capture rates of other crimes, although they suggest that crime throughout Brazil is quite high. Feelings of insecurity as well are quite high, with only $36 \%$ of individuals stating they feel safe walking alone at night. This is particularly concerning compared to regional neighbors, such as Mexico ( $42 \%$ of individuals feel safe walking alone at night), Colombia (44\%), and Chile (48\%) (OECD Better Life Index, 2020).

Here, I utilize panel data collected from two Brazilian cities - Juiz de Fora in the state of Minas Gerais and Caxias do Sul in Rio Grande do Sul. During the period of this survey, these cities were quite similar in terms of demographics and economics. In terms of security, both Juiz de Fora and Caxias do Sul represent cities of relatively middling levels of security within Brazil. Juiz de Fora had a rate of 22 homicides per 100 thousand inhabitants in 2015 while Caxias do Sul had a rate of 24.2 per 100 thousand inhabitants (Cerqueira et al., 2017). Both are slightly below the national average of 28.9 per 100 thousand inhabitants, but well above the global average of 5.9 per 100 thousand inhabitants (Data UNODC, 2017; Cerqueira et al., 2017).

In terms of the explanatory power of this case, the two cities are arguably comparable to contexts where crime is certainly present, but not the dominant narrative of many citizens day-to-day lives. It is quite possible one could compare these to other urban areas in Latin America, although they do not represent the security reality of cities known to experience extremely high crime rates, such as São Paulo or Salvador. These cities might be considered more comparable to other mid-sized Latin American cities with similar levels of crime, such as Cartagena, Colombia. Furthermore, there is notable variation within each city in terms of crime and safety, as is the case in many urban areas. Among participants of the Two-City Six-Wave survey, $40 \%$ of Juiz de Fora residents and $47 \%$ of Caxias do Sul residents reported feeling "not very safe" in their communities. Thus, overall Juiz de Fora and Caxias do Sul represent cases of intermediate to high levels of crime, although there is notable variation within each city. In such contexts, the jury is still out regarding what type of relationship we might expect between victimization and engagement. Residents in the two cities likely have less exposure to violence than those in post-conflict societies, where Blattman (2009) finds a positive relationship between victimization and engagement exists. But, it is very possible we will see variation in the effect based on differences in among community safety, as noted by Ley (2018) and Brooks (2014), who see that more insecure environments 
can preclude engagement. Thus, the context of Brazil and the two cities included in this panel provide a suitable environment to parse apart Some of the potential effects of victimization on engagement.

\section{ANALYSIS}

To determine if the relationship between victimization and political engagement is causal, and how one's personal identity, neighborhood context, or history with discrimination might influence this relationship, as mentioned I take advantage of the Two-City, Six-Wave Panel Survey, Brazil (Baker et al., 2015). Using this survey, I conduct a difference in difference (DiD) analysis on selected political engagement variables. I also replicate a portion of Bateson (2012)'s analysis, as explored below and in the online Appendix.

\section{Data and Research Design}

The Two-City, Six-Wave Panel Survey was administered in six waves during three different years (2002, 2004, and 2006) using a representative sample from the two cities, totaling about 25,000 interviews. The panel-nature of this survey allows me to establish causality in my hypothesis testing. I am able to isolate the level of political engagement of respondents before and after treatment. To measure my treatment, victimization or exposure to victimization, I rely on a question administered in Wave 4 of the survey, which asks (translated from Portuguese): "... Have you witnessed or been the victim of a crime, such as robbery, theft, or assault, in the last 12 months? Yes or no?"6. Panel-structured data is particularly valuable as it allows us to track the same individuals and isolate the individual-level effect of a treatment on a specific outcome. This stands in contrast to cross-sectional data where, due to only having access to an individual at one point in time, conclusions are often made by grouping similar individuals and finding associations between variables of interest. However, these surveys do not allow for the identification of causal, over-time patterns among these individuals. It is argued that to properly isolate causal patterns, temporal priority is a necessary condition. That is to

6. As previously noted, unfortunately, this question does include both victimization and witnessing of crime, which arguably can introduce noise into the variable. However, there is precedent in using such questions to explore the effects of crime victimization overall. For example, Bateson (2012) and Visconti (2019) both rely on similar (or the same) questions in testing the effect of victimization on various variables. In particular Visconti (2019) uses this question from this panel survey to make conclusions about the policy preferences of victims, and is able to find strong results. 
say, the cause must occur prior to the effect (Wunsch, Russo \& Mouchart, 2010). Unfortunately, with cross-sectional individual data, this necessary condition cannot be guaranteed. However, by using a panel survey that interviews the same respondents in each wave, and collects information about political engagement both pre- and post-treatment, I can guarantee this condition.

To measure political engagement, I examine three forms of non-electoral engagement: participation in political party meetings, participation in community associations ${ }^{7}$, and engagement in political conversations ${ }^{8}$.

Non-electoral engagement measures are most appropriate for this study for two main reasons. First, the survey enquires about respondents' non-electoral engagement patterns before and after victimization (which I use as a treatment), allowing it to be experimentally assessed. In terms of electoral engagement, the survey predominantly focuses on vote choice rather than including explicit measures for turnout. Further, assessing voter turnout from surveys is problematic. Research consistently shows that surveyed voter turnout does not accurately predict true turnout, and is rather subject to significant social desirability bias (Granberg \& Holmberg, 1991; Karp \& Brockington, 2005). Finally, voting in Brazil is compulsory, although the degree to which citizens abide by this law is inconsistent (Power, 2009). Thus, measuring changes in voter turnout in Brazil is likely subject to significant noise and the influence of exogenous factors. Due to these factors, electoral turnout as a measure of political engagement in this context is not appropriate; non-electoral measures provide more internally and externally consistent measures of engagement.

To code respondents of different identities, social groups, and those who have (not) experienced discrimination, I proceed as follows. Males and females are simply separated by their reported sex on the survey. Afro-Brazilians are coded as those who self-report as "Black" or "Brown," while White Brazilians are those who self-report as "White". I choose to code the poor as those whose monthly income is below the poverty line. In Brazil, this is bellow 324 Reais per month (converted

7. In particular, and as shown in the online Appendix, the question used to measure participation in community associations asks individuals about their frequency of participation in meetings of their "Associacão de Moradores" or community associations (alternatively, residents' associations). In Brazil, these associations frequently deal with political matters and work to improve community life in their area. They work on matters such as police presence, schooling, and infrastructure and frequently liaise with public officials, such as the mayors. In times of limited government action, they have also served essential roles in keeping communities safe and combatting misinformation (Watson, 2020). Scholarly work has previously documented their political ties, for example, see Gay (1990).

8. Of course, there are other forms of non-electoral engagement that might be affected. These measures are chosen because respondents were surveyed about their behavior before and after victimization, thus they permit the $\mathrm{DiD}$ design. Furthermore, these variables have ordinal outcomes, while some other measures which are surveyed have only binary outcomes. As explained in the Analysis section and the online Appendix, binary outcomes require a logit model, which is not well suited for a DiD design. 
from the international poverty line of $\$ 1.90$ per day). To isolate those who live in the most insecure neighborhoods, I rely on a question which asks respondents to rate their perception of their neighborhood's safety from very safe to very unsafe. I isolate those who self-report residing in "very unsafe" neighborhoods as belonging to the most neighborhood-insecure group, while others are coded as more neighborhood-secure. In terms of discrimination, I isolate those who report being subject to discrimination based on gender, race, neighborhood of residence, and clothing worn. Clothing serves as a proxy for perceived socioeconomic status by the discriminator?

I also employ certain strategies to ensure that my analysis has the most effective, and least biased, design. On its own, the panel survey allows for certain measures typically unavailable in non-panel surveys. Typically, researchers cannot adjust on pre-treatment covariates, as it is unclear whether covariates were influenced prior post-treatment. The panel allows me to adjust the data on covariates captured before the respondents experienced treatment (in this case, victimization). I do so by including pre-treatment measures of my outcome variables of interest (various political engagement measures) and compare them to such measures post-treatment. This corrects for various biases that adjusting for posttreatment characteristics can introduce (Rosenbaum, 1984; Rosenbaum, 2015). To do so, I isolate three variables measured before and after the treatment. These are: political party participation, engagement in group political conversations, and participation in one's community association. These variables serve as my outcome variables of interest. Each is measured in as an ordinal variable, from low levels of engagement to high.

Further, it is important that both treated and control groups compared in the models are similar in terms of covariate composition. Both groups should have comparable individuals with a similar balance of pre-treatment characteristics. As seen in Table 1, the proportion of victims vs. non-victims across various subgroups is not substantial. However, this does not capture possible other skewed characteristics of these groups, such as level of education or income. To ensure that both treated and control groups are balanced not only in treatment status, but across a range of important covariates, I create a matched data set. To do so, I take advantage of the Matchlt package (Stuart et al., 2011) to pre-process the panel data with a nonparametic matching method. This method is based on the idea that the treatment variable is not randomly assigned.

To correct for this nonrandom assignment, I employ Matchlt's "nearest neighbor" matching method, which selects the best control matches for each treated individual. I specify for the Matchlt function to use Mahalanobis distance, an

9. This measure has been used as a proxy by other authors, such as Bueno \& Dunning (2017). 
alternative method to propensity score matching. I choose this method, as compared to propensity score matching, as the popular latter method has been shown to increase imbalance, inefficiency, model dependence, and bias (King \& Nielson, 2019). Using this technique, I create a sample that is balanced across pre-treatment covariates and is even in its distribution of both treated and control observations. Similar matching approaches have been used in other analyses observing the effect of victimization utilizing this data, and have generated robust and unbiased results (e.g., Visconti, 2019). The balance across used pre-treatment covariates of the matched data set can be seen in the online Appendix.

Table 1. Subgroups by Victimization

\begin{tabular}{lcccccccc}
\hline \multicolumn{1}{c}{ Status } & Female & Males & Afro-Braz. & White & Poor & Non-Poor & Unsafe & Safe \\
\hline Vic./Witness & 288 & 277 & 130 & 274 & 198 & 481 & 189 & 491 \\
Non-Vic/Witness & 1260 & 969 & 616 & 1194 & 986 & 2051 & 639 & 2157 \\
Percent Vic & $19 \%$ & $22 \%$ & $17 \%$ & $19 \%$ & $17 \%$ & $19 \%$ & $23 \%$ & $19 \%$ \\
\hline
\end{tabular}

Source: Two-City, Six-Wave Panel Survey, Brazil (Baker et al., 2015).

Finally, the panel also suffers from a fair degree of missing data. This is common in panel data sets, as attrition rates and response missingness can be quite high. To accommodate for this absent data, I employ a multiple imputation method, Amelia II, developed by Honaker et al. (2011). This statistical package multiply imputes missing data by implementing a bootstrapping-based algorithm. It improves upon other methods used to handle missing data, such as listwise deletion or mean substitution, by filling in data in a manner that does not compromise any true relationship in the data. Rather, it allows me to include observed data from partially missing rows, whose previous missingness would impede any model from utilizing them. Thus, Amelia II also helps to overcome bias from missingness within the sample as well. Using this method, I create five "completed" data sets of missing values. Each set is filled with different imputations that allow me to incorporate the uncertainty of the missing data, and better infer results from these various iterations. These five imputed sets are then used for each model (specified below). I conduct each model five times, once on each set, and average their outputs to get the most accurate result ${ }^{10}$.

10. I impute the data sets prior to engaging in matching, as the matching process employed by Matchlt strictly requires no missing data. 


\section{ESTIMATION}

To estimate the effect of crime victimization on political engagement, I use a DiD estimator and use data from all six waves of the Two-City, Six-Wave Panel survey. I choose three ordinal measures of political engagement: political party participation, engagement in political conversations, and participation in community associations. All three measures were similarly used by Bateson (2012) to gauge engagement as well. For each measure, individuals were asked if they engage in these activities "never", "rarely", "at times", or "frequently". To measure the effect of victimization on these two variables, I run the following Ordinary Least Squares (OLS) model:

$$
Y_{i t}=B T_{t}+\gamma V_{i t}+\rho T_{t} V_{i t}+C_{i t}^{\top} \phi+\epsilon_{i}
$$

$V_{i t}$ represents the level of a certain type of engagement for individual $i$ at time $t$. $T_{t}$ is a dummy time variable that equals 1 for waves 4 through 6 and 0 for waves 1 through 3 , where the treatment begins at wave $4 . V_{i t}$ is the treatment variable which equals 1 for individuals who witnessed or experienced crime victimization within 12 months prior to wave 4 . It equals 0 for those who did not experience this treatment. These two variables, $T_{t}$ and $V_{i t}$ are then interacted to produce the coefficient $\rho$. $\rho$ represents the average treatment effect (ATE) of the treatment on individual political engagement outcomes over time. $C_{i t}$ is a vector of control variables, which depend on the nature of the exact model I run (this is explored below). To run the model appropriately for each group, and to control for potential membership in multiple groups, I specify control variables as follows for each model (for full coding procedure, see the online Appendix):

- Gender (Male vs. Female): Age, ideology (right), race (White), monthly income below poverty line, residence in an unsafe neighborhood

- Race (Afro-Brazilian vs. White): Age, ideology (right), gender (female), monthly income below poverty line, residence in an unsafe neighborhood

- Wealth (Poor vs. Non-Poor): Age, ideology (right), gender (female), race (White), residence in an unsafe neighborhood

- Neighborhood Safety (Safe vs. Unsafe): Age, ideology (right), gender (female), race (White), monthly income below poverty line

- Gender-Based Discrimination (Experienced vs. Not Experienced Discrimination): Age, ideology (right), race (White), monthly income below poverty line, residence in an unsafe neighborhood

- Racial Discrimination (Experienced vs. Not Experienced Discrimination): Age, ideology (right), gender (female), monthly income below poverty line, residence in an unsafe neighborhood 
- Wealth-Based Discrimination (Experienced vs. Not Experienced Discrimination): Age, ideology (right), gender (female), race (White), residence in an unsafe neighborhood

- Neighborhood-Based Discrimination (Experienced vs. Not Experienced Discrimination): Age, ideology (right), gender (female), race (White), monthly income below poverty line

Each measure of political engagement is tested for each pair above. In addition, I run a series of models without separating respondents into each group. The intent here is to re-test the original hypothesis that victimization leads to an increase in political engagement, but with data and a method allowing for a true test of causality. In the following section, I present the results of my tests.

\section{RESULTS}

\section{Overall Effect of Victimization on Political Engagement}

First, I examine if there is an effect of victimization on political engagement for the pooled group of respondents, without parsing apart subgroups.

Figure 1. Average Treatment Effect of Victimization on Political Engagement (All Groups)

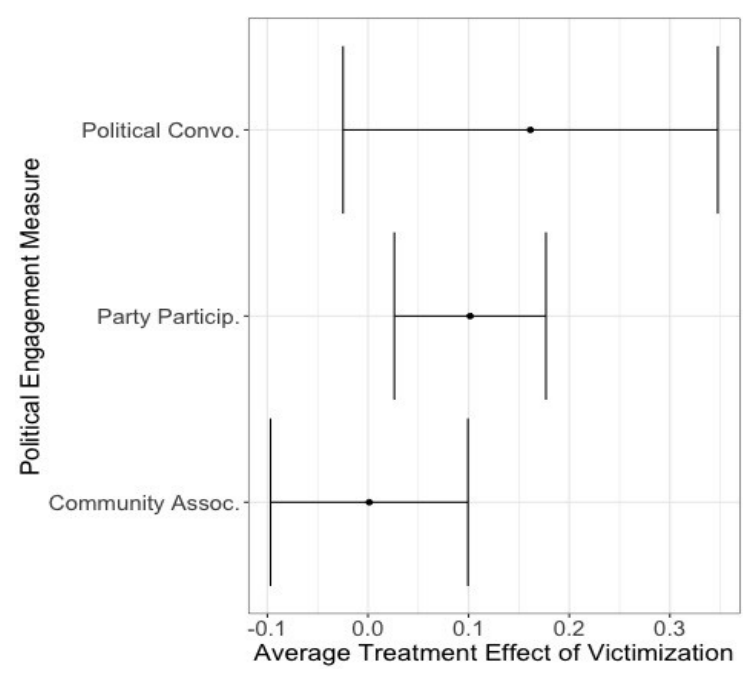

Source: Two-City, Six-Wave Panel Survey, Brazil (Baker et al., 2015) and Author's Own Elaboration. 
As previously discussed, Bateson (2012) posits that victimization leads to an increase in political engagement, across a variety of forms, using single year crosssectional data. I test this relationship with a panel data set to see if this effect truly is causal, particularly in the context of Brazil. As seen in Figure 1, there is some evidence supporting this effect, although it is limited. I find that victimization has a positive effect on political party meeting attendance, but does not have an effect on other forms of non-electoral engagement. Figure 1 presents the average treatment effect (ATE) of victimization on engagement, along with $95 \%$ confidence intervals for each estimation. Further, Tables 2 through 4 show the regression results for each model. These results are averages of the results gleaned from the same model tested on five Amelia II imputed data sets, as discussed above.

Table 2. Difference in Difference Estimation for Effect of Victimization on Political Conversations (Pooled)

\begin{tabular}{lccc}
\hline & Coefficient & Stand. Error & P Value \\
\hline Intercept & 1.866 & 0.103 & 0.000 \\
DID & 0.161 & 0.095 & 0.089 \\
Time & 0.122 & 0.076 & 0.108 \\
Treated & 0.025 & 0.078 & 0.750 \\
Ideology: Right & -0.226 & 0.048 & 0.000 \\
Below Pov. Line & -0.195 & 0.078 & 0.012 \\
Race: White & -0.042 & 0.045 & 0.348 \\
Not Safe & -0.034 & 0.056 & 0.543 \\
Female & -0.242 & 0.050 & 0.000 \\
Age & -0.004 & 0.001 & 0.005 \\
\hline
\end{tabular}

$\operatorname{Adj} R^{2}$ :

0.047

Observations: $\quad 5$ Amelia Imputed Sets $\quad(n=1026)$

Source: Two-City, Six-Wave Panel Survey, Brazil (Baker et al., 2015) and Author's Own Elaboration.

All results coded as binary list relevant categories coded as 1 , demonstrating the effect of the category on the outcome variable. The following variables are binary: Ideology: Right; Below Pov. Line; Race: White; Not Safe; Female. Age is a 
continuous variable. Full coding procedure and reference categories are included in the online Appendix.

Table 3. Difference in Difference Estimation for Effect of Victimization on Party Engagement (Pooled)

\begin{tabular}{lccc}
\hline & Coefficient & Stand. Error & P Value \\
\hline Intercept & 0.046 & 0.044 & 0.296 \\
DID & 0.102 & 0.038 & 0.008 \\
Time & 0.020 & 0.028 & 0.467 \\
Treated & 0.016 & 0.029 & 0.571 \\
Ideology: Right & -0.050 & 0.026 & 0.053 \\
Below Pov. Line & 0.014 & 0.031 & 0.645 \\
Race: White & 0.030 & 0.023 & 0.191 \\
Not Safe & 0.013 & 0.028 & 0.636 \\
Female & -0.048 & 0.021 & 0.027 \\
Age & 0.001 & 0.001 & 0.114 \\
\hline
\end{tabular}

Adj $R^{2}$ :

0.023

Observations: $\quad 5$ Amelia Imputed Sets $\quad(n=1026)$

Source: Two-City, Six-Wave Panel Survey, Brazil (Baker et al., 2015) and Author's Own Elaboration.

These results also lead one to question whether or not the originally posited correlations exist in just the context of Brazil. To determine if this association does exist, irrespective of causality, I replicate Bateson (2012)'s findings with data from the 2007 round of AmericasBarometer for Brazil (AmericasBarometer, 2020) ${ }^{11}$. The findings can be seen in Table 5.

11. This round of LAPOP was in the field between 2006 and 2007, for ease I refer to it as the 2007 round. 
Table 4. Difference in Difference Estimation for Effect of Victimization on Community Association Participation (Pooled)

\begin{tabular}{lccc}
\hline & Coefficient & Stand. Error & P Value \\
\hline Intercept & 0.053 & 0.055 & 0.335 \\
DID & 0.001 & 0.050 & 0.980 \\
Time & -0.025 & 0.037 & 0.503 \\
Treated & 0.016 & 0.039 & 0.677 \\
Ideology: Right & 0.021 & 0.032 & 0.502 \\
Below Pov. Line & 0.053 & 0.050 & 0.284 \\
Race: White & 0.078 & 0.026 & 0.002 \\
Not Safe & 0.002 & 0.032 & 0.960 \\
Female & 0.009 & 0.027 & 0.738 \\
Age & 0.004 & 0.001 & 0.000 \\
\hline
\end{tabular}

Adj $R^{2}$ :

0.014

Observations: $\quad 5$ Amelia Imputed Sets $\quad(n=1026)$

Source: Two-City, Six-Wave Panel Survey, Brazil (Baker et al., 2015) and Author's Own Elaboration.

For full details of the replication, see the online Appendix. The results of this OLS regression show that the DiD results hold when examining the entire national context of Brazil using cross-sectional data. Out of the five forms of political engagement tested, only participation in political meetings has a positive relationship with victimization. Crime victimization seems to have no relationship with community action, participation in community meetings, protest, nor interest in politics. The fact that I find this effect, and correlation, between victimization and engagement only holds when examining participation in political meetings suggests we must think much harder about under what circumstances this overall relationship exists ${ }^{12}$. But, it does suggest there seems to be a relationship between victimization and engagement in political parties that is worth exploration.

12. In addition, I replicate these findings using 2010 AmericasBarometer data from Brazil. This is the same data used by Bateson in her aggregate analysis of Latin America, but without the addition of other countries. The results, which can be found in the online Appendix, show slightly different results. In 
Table 5. Replicated Models: Correlation Between Victimization and Political Engagement, Brazil 2007

\begin{tabular}{|c|c|c|c|c|c|}
\hline & \multicolumn{5}{|c|}{ Dependent Variable } \\
\hline & $\begin{array}{c}\text { Community } \\
\text { Action }\end{array}$ & $\begin{array}{l}\text { Community } \\
\text { Meetings }\end{array}$ & Protest & Political Interest & $\begin{array}{l}\text { Political } \\
\text { Meetings }\end{array}$ \\
\hline Victimization & $\begin{array}{c}0.0502 \\
(0.0374)\end{array}$ & $\begin{array}{c}0.0146 \\
(0.0136)\end{array}$ & $\begin{array}{c}0.0100 \\
(0.0297)\end{array}$ & $\begin{array}{c}0.0091 \\
(0.0203)\end{array}$ & $\begin{array}{l}0.0174 * \\
(0.0098)\end{array}$ \\
\hline Male & $\begin{array}{l}-0.0128 \\
(0.0262)\end{array}$ & $\begin{array}{l}0.0183 * \\
(0.0093)\end{array}$ & $\begin{array}{c}0.0161 \\
(0.0217)\end{array}$ & $\begin{array}{c}0.0504 * * * \\
(0.0136)\end{array}$ & $\begin{array}{c}0.0083 \\
(0.0059)\end{array}$ \\
\hline Age & $\begin{array}{c}0.0096 * * \\
(0.0043)\end{array}$ & $\begin{array}{l}0.0025 * \\
(0.0014)\end{array}$ & $\begin{array}{l}-0.0008 \\
(0.0032)\end{array}$ & $\begin{array}{c}0.0048 * * \\
(0.0022)\end{array}$ & $\begin{array}{c}0.0017 * * \\
(0.0008)\end{array}$ \\
\hline $\mathrm{Age}^{\wedge} 2$ & $\begin{array}{c}-0.0001 \\
(0.00005)\end{array}$ & $\begin{array}{l}-0.00002 \\
(0.00002)\end{array}$ & $\begin{array}{l}0.000000 \\
(0.00003)\end{array}$ & $\begin{array}{c}-0.00004 * \\
(0.00002)\end{array}$ & $\begin{array}{c}-0.00002 * * \\
(0.00001)\end{array}$ \\
\hline Econ & $\begin{array}{l}0.0064 \\
0.0148)\end{array}$ & $\begin{array}{l}-0.0001 \\
(0.0052)\end{array}$ & $\begin{array}{l}-0.0093 \\
(0.0142)\end{array}$ & $\begin{array}{c}0.0162 * * \\
(0.0080)\end{array}$ & $\begin{array}{l}-0.0013 \\
(0.0035)\end{array}$ \\
\hline Educ & $\begin{array}{c}0.0072 * * \\
(0.0030)\end{array}$ & $\begin{array}{l}0.0018 * \\
(0.0010)\end{array}$ & $\begin{array}{c}0.0076 * * * \\
(0.0024)\end{array}$ & $\begin{array}{c}0.0129 * * * \\
(0.0016)\end{array}$ & $\begin{array}{c}0.0010 \\
(0.0006)\end{array}$ \\
\hline Urban & $\begin{array}{c}-0.0182 * * \\
(0.0091)\end{array}$ & $\begin{array}{c}0.0003 \\
(0.0034)\end{array}$ & $\begin{array}{c}0.0011 \\
(0.0096)\end{array}$ & $\begin{array}{l}-0.0043 \\
(0.0048)\end{array}$ & $\begin{array}{c}-0.0041 * \\
(0.0022)\end{array}$ \\
\hline Constant & $\begin{array}{l}-0.0100 \\
(0.1044)\end{array}$ & $\begin{array}{c}0.2207 * * * \\
(0.0381)\end{array}$ & $\begin{array}{c}0.3835 * * * \\
(0.0974)\end{array}$ & $\begin{array}{c}0.2351 * * * \\
(0.0545)\end{array}$ & $\begin{array}{c}0.2426^{* * *} \\
(0.0233)\end{array}$ \\
\hline
\end{tabular}

Source: LAPOP 2007 and Author's Own Elaboration.

\section{EXPLORING SUBGROUPS}

The above evidence indicates that there is only a causal relationship between victimization and participation in political party meetings, and that no relationship exists among the other two measures in Brazil. However, it is still possible that further results exist when I examine varying contexts, group identities, and experiences among the sample population. For example, individuals of identities that

addition, it includes further variables which appear in the 2010 round of the survey, but were not yet included in the $2006 / 2007$ round. 
have seen a history of government responsiveness, such as males or the socioeconomically advantaged, could experience a shock to their engagement following victimization. Further, we might see a reduction in political engagement among other subgroups.

The results provided in this section show that, upon further analysis, it seems that individuals of differing subgroups respond to victimization in distinct ways. In Figures 2 through 9, I again present the ATE for victimization on each selected mode of political engagement with $95 \%$ confidence intervals. However, in these figures they are separated by subgroup (e.g., gender is separated by male vs. female, neighborhood by safe vs. unsafe, and so forth). The coefficients, standard errors, and $p$-values for each model can be found in the online Appendix.

A portion of the estimated coefficients are statistically significant, suggesting a shock in engagement following victimization. However, the confidence intervals for each group always overlap. This suggests that although there is reason to believe certain subgroups might experience stronger shocks to engagement following victimization, further testing must be done to determine if the difference between the two groups is significant and noteworthy.

Select measures show ATEs of statistical significance. Interestingly, although there was no ATE of victimization on political conversations in the pooled sample, we see White Brazilians are more likely to engage in political conversations after victimization. However, this was not true of Afro-Brazilians. These results must be interpreted carefully: for White Brazilians, the results are statistically significant. Yet, while results are different from zero, they are not statistically different from the ATE for Afro-Brazilians. Similarly, we see that residents of safe neighborhoods do experience a positive shock to their participation in political party meetings, while those who reside in unsafe neighborhoods do not (Figure 5). Men also experience this same shock to their engagement, while women do not (Figure 2). Again, the confidence intervals for each group overlap, but this suggests that at minimum those residing in safe neighborhoods are driving the effect seen in the pooled sample.

When examining the role of discrimination, we see some interesting results as well. Each group that experienced no discrimination on the basis of gender, race, clothing (socioeconomic status), or neighborhood of residence see a positive and statistically significant shock to their participation in political party meetings (Figures 6-9). However, again the confidence intervals do overlap with those corresponding to the ATE of of indviduals who report no discrimination. Among the other two forms of engagement, no statistically significant effect is seen among both those who experienced or did not experience discrimination. 
Figure 2. DID Estimation of Victimization and Gender

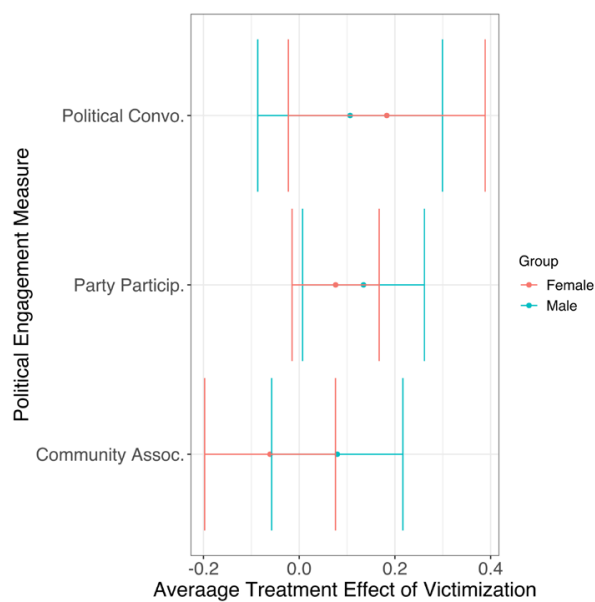

Figure 4. DID Estimation of Victimization and Poverty

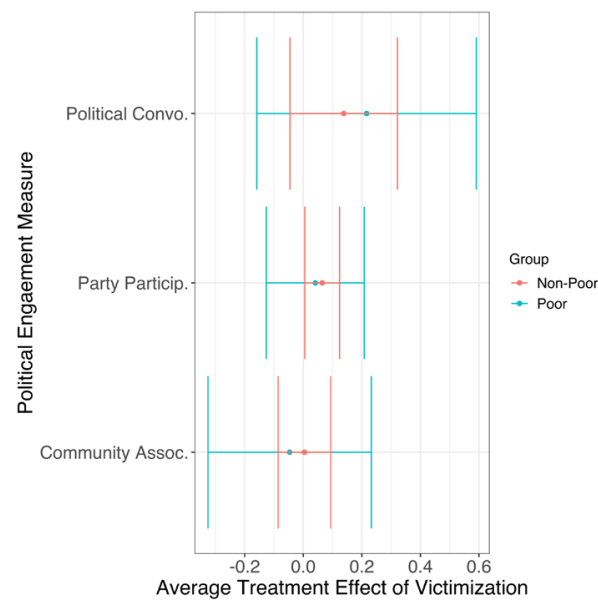

Figure 3. DID Estimation of Victimization and Race

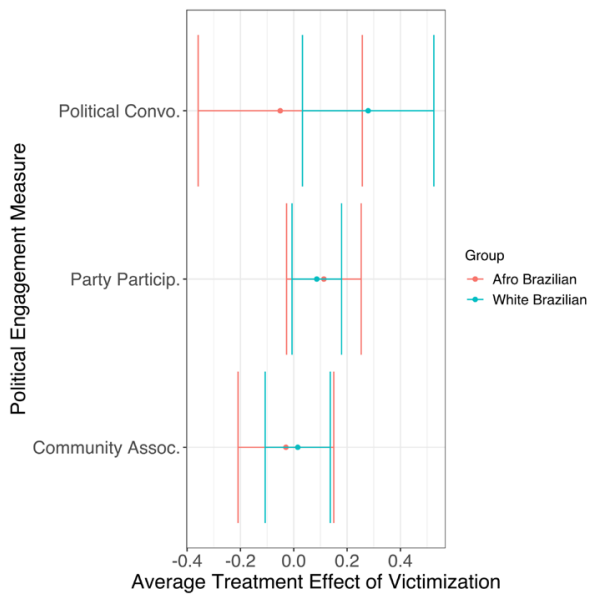

Figure 5. DID Estimation of Victimization and Neighborhood

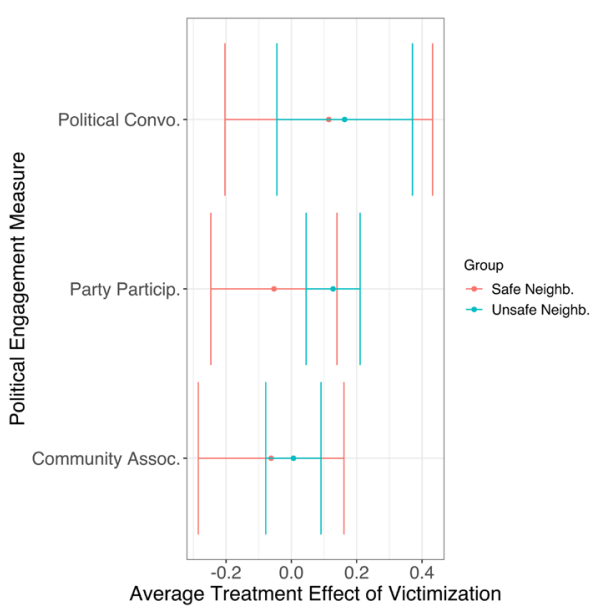

Source: Two-City, Six-Wave Panel Survey, Brazil (Baker et al., 2015) and Author's Own Elaboration.

Overall, the results show some support for the expected relationships between neighborhood of residence and various individual identities in terms of the role that victimization plays in affecting engagement. Further, we see some evidence that those who do not report experiencing discrimination do experience a positive 
shock to their participation in political party meetings, while those who do report experiencing discrimination do not see such an effect.

Figure 6. DID Estimation of Victimization and Gender-Based Discrimination

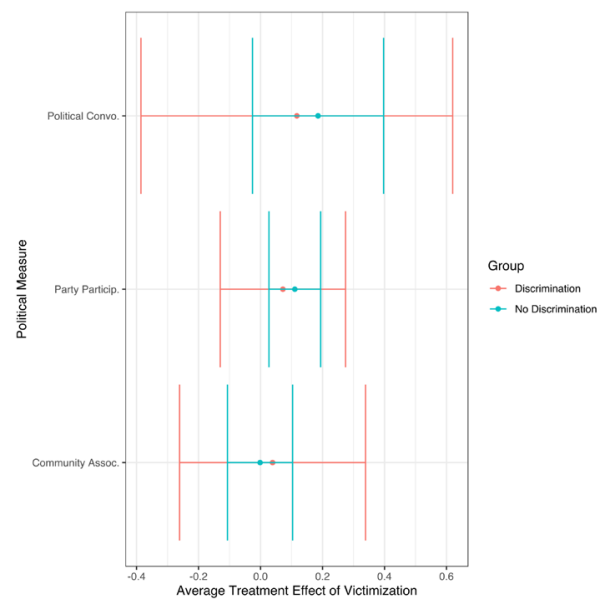

Figure 8. DID Estimation of Victimization and Poverty-Based Discrimination (Clothes Proxy)

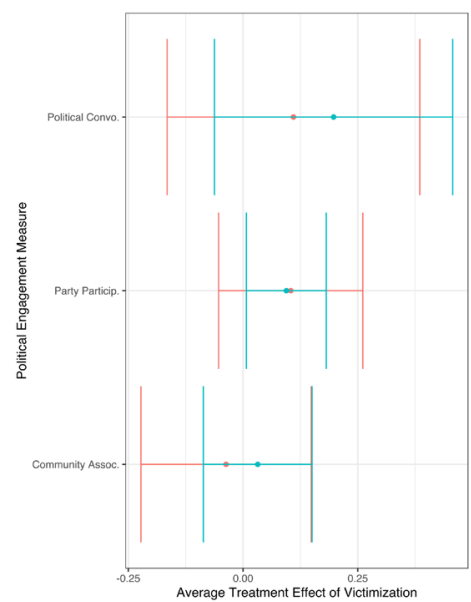

Figure 7. DID Estimation of

Victimization and Race-Based Discrimination

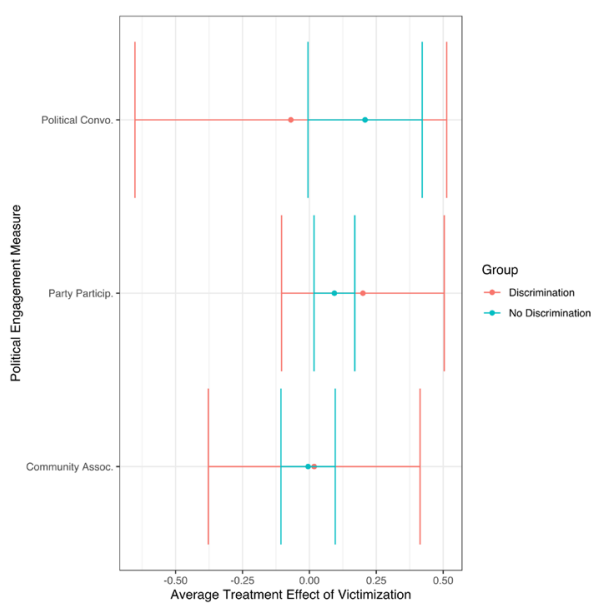

Figure 9. DID Estimation of Victimization and Neighborhood-Based Discrimination

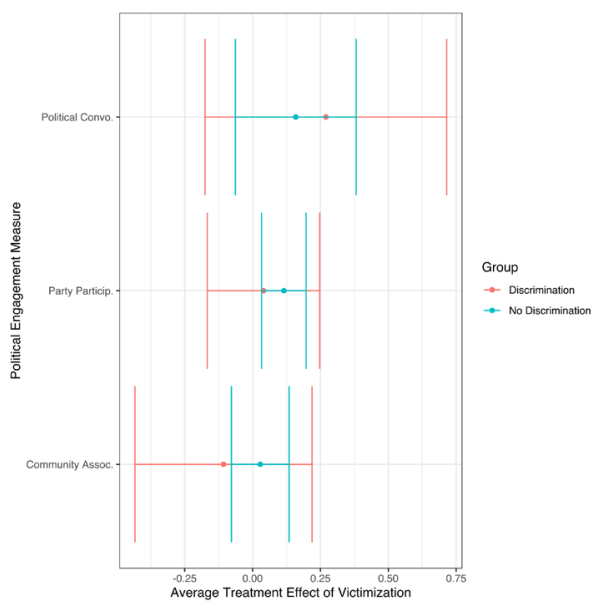

Source: Two-City, Six-Wave Panel Survey, Brazil (Baker et al., 2015) and Author's Own Elaboration. 


\section{DISCUSSION}

It has been widely hypothesized that victimization or exposure to violence can impact citizens' political engagement. However, most evidence in support of this hypothesis has relied on survey data that, strictly speaking, can only show an associational relationship. Using data from the Two-City Six-Wave panel survey (Baker et al., 2015) administered in Brazil between 2002 and 2006, I set out to examine this hypothesis in a way that can better adjudicate if there is indeed a causal relationship between victimization and engagement. The findings from this analysis reveal various noteworthy points worthy of further discussion.

First, past analyses examining the relationship between victimization and political engagement have, in multiple cases, revealed clear, statistically significant relationships between these variables. In many of these studies, these results are framed as causal (with victimization impacting engagement). My analysis calls into question both the association between these variables and their causal relationship in the context of Brazil. In particular, I find that this relationship seems to be participation mode specific in Brazil. There is no causal relationship between victimization and two important measures of political engagement - participation in community associations (the Associação de Moradores do Barrio, in Brazil) and engagement in political conversations. In previous studies which rely on non-panel survey data, such as Bateson (2012), it is argued that there is a causal relationship between these variables. However, I do find evidence for a causal relationship between victimization and engagement in political party meetings. My results and analysis strategy overall suggest that we need more, ideally panel, studies of the relationships between victimization and different types of political engagement.

There are various possible explanations. First, it could be that participation in party meetings is a type of engagement that attracts a certain group of individuals who are more likely to participate and seek change after victimization; this is supported by past work examining political engagement patterns among different types of citizens (Li \& Marsh, 2008). It is also possible that participating in political party meetings is perceived to elicit change relevant to reducing crime, thus resulting in an increased response in this domain. Further, it could be other specific factors relevant to each participation domain which might vary across country contexts (Bennett, Flickinger \& Rhine, 2000; Vráblíková, 2014).

In examining this result further, it is evident that there are significantly fewer people, both prior to and following possible victimization, that engage in political party meetings. Across relevant waves, we see on average 9 percent of individuals participating in political party meetings (increase from 7 to 11 percent from Wave 1 to Wave 4). This is significantly lower than engagement in both neighborhood association meetings and political conversations, with about 20 and 79 percent of respondents on average, respectively, reporting participation across waves. 
Participation in neighborhood associations barely changed across waves, while engagement in political conversations increased by about 11 percent ${ }^{13}$. However, such changes are across both victims and non-victims, thus do not represent changes in response to the treatment.

This lower level of overall participation in political party meetings might be a clue to understand why we see an effect of victimization present only with respect to this mode of engagement. It is possible that individuals who choose to participate in party meetings are more politically knowledgeable, savvy, and/or engaged overall. Following victimization, they may see value in attending such meetings to instigate change in the political system; for others this may not be the case. However, more research into the differences between these populations and the exact motivations for increased engagement must be explored to identify this mechanism.

Furthermore, the analyses of subgroups indicates that the effect of victimization on participation in political party meetings is largely driven by men and residents of safe neighborhoods. In addition, it seems that those who have not experienced discrimination on the basis of gender, race, poverty, nor neighborhood of residence also contribute to this effect (Figures 2-9). Thus, there might be further factors related to this population that explain why we see increased participation in party meetings among them following victimization, but not among others. As discussed earlier, there are clearly different engagement patterns among such populations, but these have been explored very little in the context of victimization.

Varying engagement patterns could be driven by factors related to representation in political parties. For example, at the time of the survey utilized here, women in Brazil saw little representation in political office (Miguel, 2008). Quotas were introduced to ameliorate this, with some effects. It is possible that certain groups, such as women, do not increase their participation in parties after victimization due to barriers to entry and possible lack of participation among their ingroup. Others however, such as men and those who have not experienced discrimination, might see political parties as a viable option to instigate change. In addition to these results regarding participation in political party meetings, the disaggregated analysis revealed differences among White versus Afro-Brazilians in political conversations, an effect masked by the pooled sample. White Brazilians in the survey sample increase their engagement in political conversations following victimization, while this effect does not exist for Afro-Brazilians. Notably, the confidence intervals of the ATEs once again overlap, but the result nonetheless suggests future investigation should be conducted to explore patterns of political conversation following

13. Neighborhood association participation is recorded to be 20.4 percent in Wave $1,20.6$ percent in Wave 4, and 20.3 percent in Wave 5. Engagement in political conversations is recorded to be 71.8 percent in Wave 1, 80.5 percent in Wave 4, 81 .3 percent in Wave 5, and 82.7 percent in Wave 4. This is irrespective of the level of participation, and only accounts for a participation level of greater than "never." 
victimization. In addition to varying results among subgroups for participation in political party meetings, this result further suggests that various subgroups of the population engage in politics differently following victimization.

It is also worth noting that certain control variables were included in this analysis which were not incorporated in some other previous scholarly work. Namely, although (Bateson, 2012) includes a variety of controls in her analysis, such as socioeconomic status and age, race and/or ethnic identity is not included. The analysis here suggests this is an important factor to consider when examining the effect of victimization on political engagement. Furthermore, few analyses on this topic have considered the role of discrimination. The results presented here also suggest that discrimination should be considered an important factor worth including in future analyses on the political ramifications of violence. Finally, this analysis suggests that country context is of paramount importance. Many previous studies do take a within-country research approach (Brooks, 2014; Blattman, 2009; Trelles \& Carreras, 2012; Ley, 2018), and this study confirms this may be the most prudent method. Apart from contrasting causal findings, the replication analysis included also suggests that associational relationships in Brazil differ from results found at the regional level. That is to say, although pooled analyses of Latin America (and other regions) point to associational relationships between victimization and many forms of engagement, when examining just the Brazilian context, many of these relationships do not hold. This causal analysis also supports this finding.

\section{CONCLUSION}

Previous research on victimization and political engagement has seen substantial disagreement about the relationship between these two factors. Among both those studying electoral and non-electoral engagement, there are conflicting arguments regarding how violence and victimization affect citizens' engagement. Some argue it positively affects engagement, resulting in heightened engagement across modes such as protest, community association involvement, and even voting (e.g., Bateson, 2012; Oosterhoff et al., 2018; Blattman, 2009). Others have argued that the relationship between violence and engagement is actually negative; those who experience violence or victimization in fact engage less in politics (e.g., Trelles \& Carreras, 2012; Brooks, 2014; Ley, 2018). In this paper, I seek to bring more clarity to this debate in two main ways. First, I re-test the effect of victimization on engagement in a clearly causal manner by utilizing individual-level panel data and a difference-in-difference design. This method allows me to make causal conclusions about how exactly one's victimization experience affects political engagement. In particular, I examine non-electoral engagement. Second, I examine how specific contexts, identities, and one's experience with discrimination might affect this 
relationship. I examine the role of community safety, gender, race, socioeconomic status, and discrimination based on these categories as well and how the effect of victimization on engagement differs among these subgroups.

Using data from the Two-City, Six-Wave Panel Survey administered in Juiz de Fora and Caxias do Sul, Brazil between the years of 2002 and 2006, I make a handful of contributions to this endeavor. First, I find that across the pooled sample victimization does affect political engagement, but this effect seems to be dependent on the mode of engagement. Across the three modes explored (participation in political party meetings, participation in neighborhood associations, and engagement in political conversations), engagement only increases in political party meetings. All other measures see no change.

Furthermore, there is some evidence that context, certain identities, and experience with discrimination do influence the overall relationship between victimization and engagement. However, this effect is tenuous. For example, we see men experience a positive shock to engagement following victimization that is statistically significant. We do not see a statistically significant shock among women. However, $95 \%$ confidence intervals for such results always overlap, suggesting further adjudication must be done to discover how robust such a difference in effect truly is.

These results provide an important contribution to the study of victimization and engagement, but are notably also specific to the context in which the survey was administered. Caxias do Sul and Juiz de Fora are not an accurate national representation of Brazil. However, results from these cities do help us understand how victimization and engagement relate to one another in contexts of middling, urban violence. Of course, the security situation within these two cities is variable as well. Results further indicate there might be a relationship as well between the safety of one's neighborhood and the effect of victimization on engagement. This comports with previous studies that suggest such a relationship (e.g., Trelles \& Carreras, 2012; Brooks, 2014; Ley, 2018). Notably, further research should be done to conclude how the relationship between victimization and engagement might function in contexts with lower levels of violence and potentially in rural areas.

This research still leaves a variety of questions unanswered, and suggests multiple avenues for future research. First, it demonstrates that the effect of violence on engagement is specific to the mode of engagement. This suggests that further research should be done to explore this difference more in depth and with more modes of engagement. Does violence affect protest differently, as well? In addition, it is worth exploring if engagement increases in other realms of society following victimization. For example, do victims increase their involvement in religious organizations, vigilante groups, or neighborhood watch groups? Particularly in the context of Brazil where informal governance is common (such as in lower income communities), do we see individuals seek out change from non-state governance groups instead? But, as this piece suggests, it is very important in assessing these 
questions that researchers employ strategies that can truly reveal the causal nature of such a relationship. This study employs a difference in difference framework, taking advantage of a six wave panel survey, to show how engagement changes before and after victimization across the same individuals. Other research strategies could also be employed to accomplish this goal, such as more qualitative methods, including interviews, or quantitative methods that allow for causal conclusions, such as experiments.

\section{REFERENCES}

AmericasBarometer (2020). The Latin American Public Opinion Project (LAPOP), www.LapopSurveys.org.

Baker, A., Ames, B., Sokhey, A. E., Renno, L. R. (2015). Replication data for: The dynamics of partisan identification when party brands change: The case of the works party in Brazil. Harvard Dataverse. https://doi.org/10.7910/DVN/XSCFX5

Bardall, G., Bjarnegård, E., \& Piscopo, J. M. (2020). How is political violence gendered? Disentangling motives, forms, and impacts. Political Studies, 68(4), 916-935.

Barreto, M. A., \& Woods, N. D. (2005). The anti-Latino political context and its impact on GOP detachment and increasing Latino voter turnout in Los Angeles County. In G.M. Segura S. Bowler (Eds.). Diversity in democracy: Minority representation in the United States. Charlottesville: University of Virginia Press.

Bateson, R. (2012). Crime victimization and political participation. American Political Science Review, 106(3), 570-587. https://doi.org/10.1017/S0003055412000299

Bennett, S. E., Flickinger, R. S., \& Rhine, S. L. (2000). Political talk over here, over there, over time. British Journal of Political Science, 30(1), 99-119.

Blattman, C. (2009). From violence to voting: War and political participation in Uganda. American Political Science Review, 103(2), 231-247.

Brady, H. E., Verba, S., \& Schlozman, K. L. (1995). Beyond SES: A resource model of political participation. American Political Science Review, 89(2), 271-294.

Bravo, C., and Maldonado G. (2012). Las balas y los votos: ¿qué efecto tiene la violencia sobre las elecciones? In J. A. Aguilar (Ed.). Las bases sociales de crimen organizado y la violencia en México. México: Centro de Investigación y Estudios em Seguridad.

Brooks, S. M. (2014). Insecure democracy: Risk and political participation in Brazil. The Journal of Politics, 76(4), 972-985.

Bueno, N. S., \& Dunning, T. (2017). Race, Resources, and Representation Evidence from Brazilian politicians. World Politics, 69(2), 327-365.

Bueno, N. S., \& Fialho, F. M. (2009). Race, resources, and political participation in a Brazilian city. Latin American Research Review, 44(2), 59-83.

Cerqueira, D., Lima, R. S. D., Bueno, S., Valencia, L. I., Hanashiro, O., Machado, P. H. G., \& Lima, A. D. S. (2017). Atlas da Violência 2017. URL: https://www.ipea.gov.br/ atlasviolencia/download/24/atlas-da-violencia-2020

Cicatiello, L., Ercolano, S., \& Gaeta, G. L. (2015). Income distribution and political participation: a multilevel analysis. Empirica, 42(2), 447-479. 
Data UNODC by the United Nations Office on Drugs and Crime. URL: https://dataunodc. un.org

Desposato, S., \& Norrander, B. (2009). The gender gap in Latin America: Contextual and individual influences on gender and political participation. British Journal of Political Science, 39(1), 141-162.

Flesken, A., \& Hartl, J. (2020). Ethnicity, inequality, and perceived electoral fairness. Social Science Research, 85, 102363. https://doi.org/10.1016/j.ssresearch.2019.102363

Gay, R. (1990). Neighborhood associations and political change in Rio de Janeiro. Latin American Research Review, 25(1), 102-118.

Granberg, D., \& Holmberg, S. (1991). Self-reported turnout and voter validation. American Journal of Political Science, 35(2), 448-459.

Hadzic, D., Carlson, D., \& Tavits, M. (2020). How exposure to violence affects ethnic voting. British Journal of Political Science, 50(1), 345-362.

Hadzic, D., \& Tavits, M. (2019). The gendered effects of violence on political engagement. The Journal of Politics, 81(2), 676-680.

Honaker, J., King, G., \& Blackwell, M. (2011). Amelia II: A program for missing data. Journal of Statistical Software, 45(7), 1-47.

Janusz, A., \& Campos, L. A. (2018). Candidate Advertisements and Afro-Brazilian Political Marginalization. Latin American Research Review, Forthcoming. Available at SSRN: https://ssrn.com/abstract $=3690578$

Karp, J. A., \& Brockington, D. (2005). Social desirability and response validity: A comparative analysis of overreporting voter turnout in five countries. The Journal of Politics, 67(3), 825-840.

King, G. \& Nielson, R. (2019). Why Propensity Scores Should Not Be Used for Matching. Political Analysis, 27(4), 435-454.

Laterzo, I. 2020. Don't Call the Police? Measuring and Explaining the Dark Figure of Crime, Working Paper.

Leighley, J. E., \& Vedlitz, A. (1999). Race, ethnicity, and political participation: Competing models and contrasting explanations. The Journal of Politics, 61(4), 1092-1114.

Ley, S. (2013). An Overview of the Political Consequences of Crime and Insecurity in Latin America. Latin America Policy Journal, 2, 21-26.

Ley, S. (2017). Electoral accountability in the midst of criminal violence: Evidence from Mexico. Latin American Politics and Society, 59(1), 3-27.

Ley, S. (2018). To vote or not to vote: how criminal violence shapes electoral participation. Journal of Conflict Resolution, 62(9), 1963-1990.

Li, Y., \& Marsh, D. (2008). New forms of political participation: Searching for expert citizens and everyday makers. British Journal of Political Science, 247-272.

Miguel, L. F. (2008). Political representation and gender in Brazil: Quotas for women and their impact. Bulletin of Latin American Research, 27(2), 197-214.

OECD Better Life Index. (2020). OECD. URL: http://www.oecdbetterlifeindex.org/ countries/brazil/

Oosterhoff, B., Kaplow, J. B., Layne, C. M., \& Pynoos, R. S. (2018). Civilization and its discontented: Links between youth victimization, beliefs about government, and political participation across seven American presidencies. American Psychologist, 73(3), 230-242. 
Oskooii, K. A. (2016). How discrimination impacts sociopolitical behavior: A multidimensional perspective. Political Psychology, 37(5), 613-640.

Oskooii, K. A. (2020). Perceived discrimination and political behavior. British Journal of Political Science, 50(3), 867-892.

Power, T. J. (2009). Compulsory for whom? Mandatory voting and electoral participation in Brazil, 1986-2006. Journal of Politics in Latin America, 1(1), 97-122.

Rosenbaum, P. R. (1984). The consequences of adjustment for a concomitant variable that has been affected by the treatment. Journal of the Royal Statistical Society: Series A (General), 147(5), 656-666.

Rosenbaum, P. R. (2015). How to see more in observational studies: Some new quasi-experimental devices. The Annual Review of Statistics and Its Applications, 2, 21-48.

Schildkraut, D. J. (2005). The rise and fall of political engagement among Latinos: The role of identity and perceptions of discrimination. Political Behavior, 27(3), 285-312.

Stuart, E. A., King, G., Imai, K., \& Ho, D. (2011). Matchlt: nonparametric preprocessing for parametric causal inference. Journal of Statistical Software, 42(8).

Telles, E. (2007). "Racial Discrimination and Miscegenation: The Experience in Brazil." UN Chronicle. The United Nations. URL: https://www.un.org/en/chronicle/article/ racial-discrimination-and-miscegenation-experience-brazil

Trelles, A., \& Carreras, M. (2012). Bullets and votes: Violence and electoral participation in Mexico. Journal of Politics in Latin America, 4(2), 89-123.

Van Deth, J. W. (2014). A conceptual map of political participation. Acta Politica, 49(3), 349-367.

Visconti, G. (2020). Policy preferences after crime victimization: panel and survey evidence from Latin America. British Journal of Political Science, 50(4), 1481-1495.

Vráblíková, K. (2014). How context matters? Mobilization, political opportunity structures, and nonelectoral political participation in old and new democracies. Comparative Political Studies, 47(2), 203-229.

Watson, K. (2020). Coronavirus: Brazil's favela residents organise to stop the spread. BBC News. URL: https://www.bbc.com/news/world-latin-america-52137165

Williams, M. S. (2000). Voice, trust, and memory: Marginalized groups and the failings of liberal representation. Princeton University Press.

Wunsch, G., Russo, F., \& Mouchart, M. (2010). Do we necessarily need longitudinal data to infer causal relations? Bulletin of Sociological Methodology/Bulletin de Méthodologie Sociologique, 106(1), 5-18. 
